\title{
Wear of Fluorapatite Single Crystals: III. Classification of Surface Failure
}

\author{
J. M. POWERS and R. G. CRAIG \\ School of Dentistry, University of Michigan, Ann Arbor, Michigan 48104, USA
}

\begin{abstract}
Modes of surface failure observed for natural fluorapatite single crystals under sliding were classified and related to wear and frictional behavior. The basal surfaces exhibited brittle or ductile failure depending on the combination of load and slider design. The transition occurred at penetrations of 0.3 to $0.5 \mu \mathrm{m}$.
\end{abstract}

Examination of modes of surface failure of single crystals damaged as a result of a frictional process has been of growing interset in the past two decades. The early work of King and Tabor ${ }^{1}$ demonstrated that brittle materials $(\mathrm{NaCl})$ could exhibit plastic deformation in the region of surface contact between the material and slider. Since then a number of investigators have observed similar behavior for a variety of nonmetallic single crystals. ${ }^{2-4}$ Plastic behavior for a single crystal of $\mathrm{NaCl}$ also has been observed under conditions of abrasion. ${ }^{5}$ Wright, ${ }^{6}$ who used abrasive technique of Dobson and Wilman, ${ }^{5}$ has suggested that human dental tissue might exhibit a ductile behavior for indentations of the order of 0.5 micrometers $(\mu \mathrm{m})$.

It was the purpose of this study to classify the modes of surface failure observed for natural fluorapatite single crystals under sliding and to relate these modes to observations of wear and frictional behavior reported in parts one and two of this investigation. ${ }^{7,8}$

This investigation was supported by USPHS Training Grant DE-00181 and Research Grant DE-02415 from the National Institute of Dental Research, National Institutes of Health, Bethesda, Md.

This paper was presented in part at the 49th general session of the IADR, Chicago, Ill, March 19, 1971.

Received for publication March 15, 1971.

\section{Materials and Methods}

Diamond sliders of known geometry were slid across the basal surfaces of natural fluorapatite single crystals in a dry environment. Observations of modes of surface failure were made based on a series of three, one-traversal passes on each of two crystals for a given condition. The effect of crystallographic direction on failure modes was not evaluated in this initial study.

Fluorapatite single crystals* were given a polishing and surface treatment procedure as described in part one of this investigation. ${ }^{7}$ The apparatus used for scratching the surface of a specimen has been described in detail earlier. ${ }^{7,8}$

The wear scars, as observed from photographs used to measure the track width, ${ }^{7}$ were classified on a one to five ordinal scale, which is illustrated in Figure 1. This scale was developed in an attempt to discriminate among three major types of failure modes: a ductile mode characterized by smooth grooves (class 1), a cleavage mode characterized by tensile cracks (class 3 ), and a chipping mode characterized by extensive chevron formation (crystallographically nonspecific fracture; class 5). Classes 2 and 4 represented modes of failure somewhere in between the modes described. This scale was meant to characterize surface failure only and did not attempt to account for visible subsurface deformation or fracture.

The factorial design used in previous studies $^{7,8}$ was followed in this investigation. The factors examined in this design are

* Southwest Scientific Co., Box 10, Hamilton, Mont. 


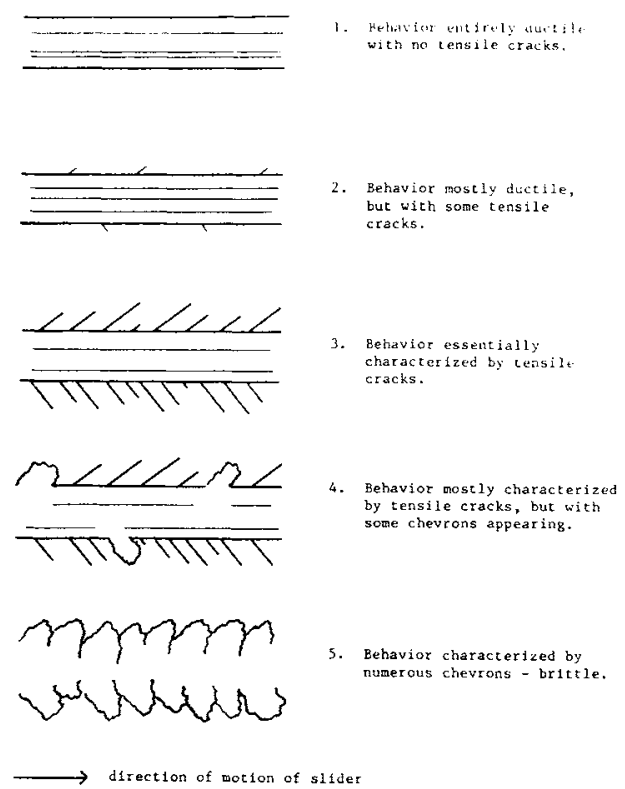

FIG 1.-Failure classification scale.

summarized in Table 1. An attempt was made to analyze the raw failure classification data by means of nonparametric statistics, ${ }^{9}$ because the analysis of variance and multiple comparisons techniques used previously ${ }^{7,8}$ require data of a higher order.

\section{Results}

Examples of class 1 through class 5 types of failure modes are presented in Figures 2 through 6 , respectively. In these examples the direction of relative motion

TABLE 1

EXPERIMENTAL DESIGN FACTORS

\begin{tabular}{lcc}
\hline \multicolumn{1}{c}{ Factor } & Levels & Comments \\
\hline Specimen & 2 & $\begin{array}{c}\text { Two crystals (three rep- } \\
\text { lications per crystal) }\end{array}$ \\
Slider speed & 2 & 0.025 and $0.076 \mathrm{~cm} / \mathrm{second}$ \\
Load & 5 & $10,25,50,100$, and 500 \\
gm $\left(A_{1}\right.$ through $A_{5}$, \\
respectively) \\
Slider design & $5 \quad \begin{array}{l}75^{\circ} \text { cone, } 0.018 \mathrm{~cm} \text { radius } \\
\end{array}$ & $\begin{array}{l}75^{\circ} \text { cone, } 0.064 \mathrm{~cm} \text { radius } \\
104^{\circ} \text { cone, } 0.005-0.008 \mathrm{~cm}\end{array}$ \\
& radius \\
& $123^{\circ}$ cone, $0.005-0.008 \mathrm{~cm}$ \\
radius & $143^{\circ}$ cone, $0.005-0.008 \mathrm{~cm}$ \\
& radius $\left(B_{1}\right.$ through $B_{5}$, \\
& respectively)
\end{tabular}

of the slider was from the lower left to the upper right. As is clear from these photographs, the ductile failure (class 1) was characterized by smooth grooves with no evidence of surface tensile cracks. The class 2 failure was similar, but evidence of minor surface tensile cracks was observed. The cleavage failure (class 3 ) was characterized by numerous surface tensile cracks, although the center of the groove was ductile in nature. The class 4 failure was similar to class 3, but evidence of chevron formation or chipping was observed. The chipping mode of failure (class 5) was characterized by extensive chevron formation with the center of the groove no longer showing much evidence of ductility. In all instances the tensile cracks or chevrons formed pointed toward the origin of their formation (ie, opposite to the direction of relative motion of the slider).

The raw data for the experimental design are presented in Table 2. Attempts to evaluate these data by means of nonparametric statistics were unsuccessful because of the complexity of the factorial design. In spite of this shortcoming, it was thought that there were observable trends.

The effect of specimen $(C)$ on failure

TABLE 2

Raw Failure Classification Data

\begin{tabular}{cccccc}
\hline $\begin{array}{c}\text { Factor } \\
\text { Level }\end{array}$ & $C_{1}$ & $C_{2}$ & $\begin{array}{c}\text { Factor } \\
\text { Leve1 }\end{array}$ & $C_{1}$ & $C_{2}$ \\
\hline$A_{1}$ & & \multicolumn{5}{c}{$A_{2}$} \\
$B_{1}$ & 111 & 111 & $B_{1}$ & 111 & 112 \\
$B_{2}$ & 111 & 111 & $B_{2}$ & 111 & 111 \\
$B_{3}$ & 331 & 114 & $B_{3}$ & 555 & 555 \\
$B_{4}$ & 213 & 322 & $B_{4}$ & 454 & 354 \\
$B_{5}$ & 312 & 211 & $B_{5}$ & 333 & 333 \\
$A_{3}$ & & & $A_{4}$ & & \\
$B_{1}$ & 111 & 333 & $B_{1}$ & 122 & 211 \\
$B_{2}$ & 111 & 111 & $B_{2}$ & 111 & 111 \\
$B_{3}$ & 445 & 544 & $B_{3}$ & 555 & 555 \\
$B_{4}$ & 544 & 545 & $B_{4}$ & 554 & 454 \\
$B_{5}$ & 444 & 444 & $B_{5}$ & 544 & 444 \\
$A_{5}^{\dagger}$ & & & $A_{5}^{\ddagger}$ & & \\
$B_{1}$ & 454 & 334 & $B_{1}$ & 544 & 554 \\
$B_{2}$ & 122 & 331 & $B_{2}$ & 511 & 212 \\
$B_{3}$ & 555 & 555 & $B_{3}$ & 555 & 555 \\
$B_{4}$ & 555 & 555 & $B_{4}$ & 555 & 555 \\
$B_{5}$ & 555 & 555 & $B_{5}$ & 555 & 555 \\
\hline$A_{4}$ & & & & 555 &
\end{tabular}

* $A, B$ and $C$ refer to load, slider design, and crystal, respectively.

$\dagger$ Speed of $0.025 \mathrm{~cm} /$ second.

Speed of $0.076 \mathrm{~cm} / \mathrm{second}$. 


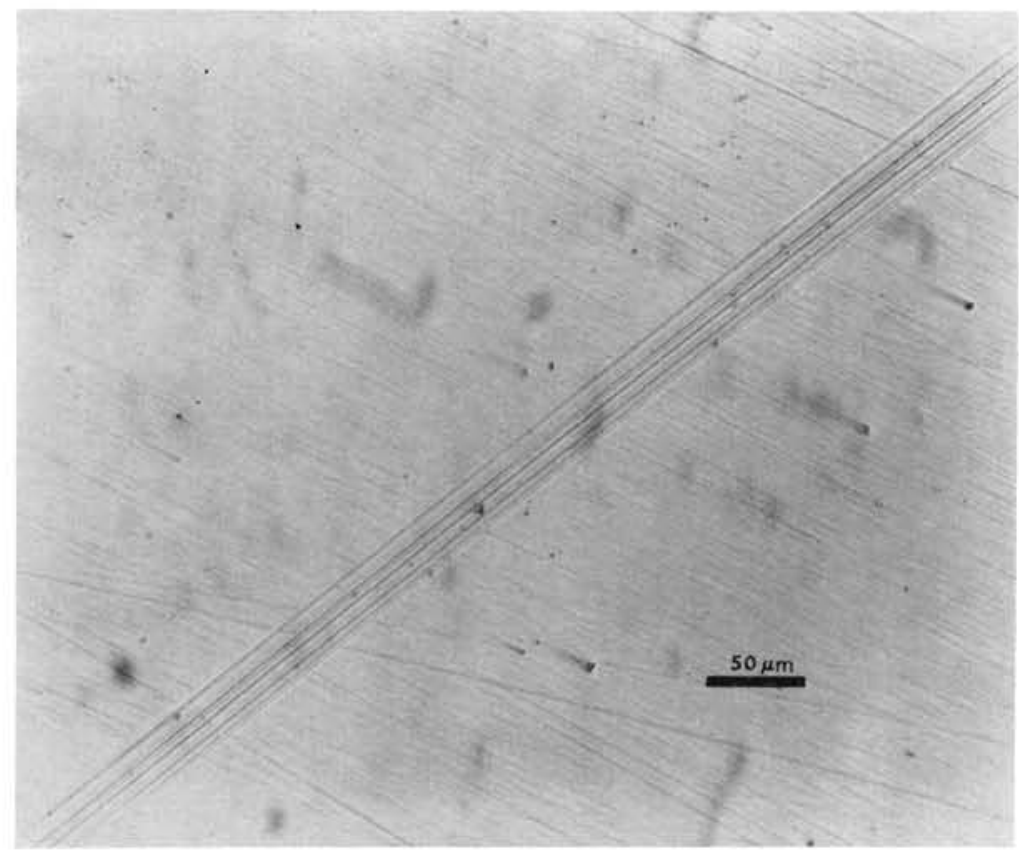

FIG 2.-Class 1 failure (ductile mode).

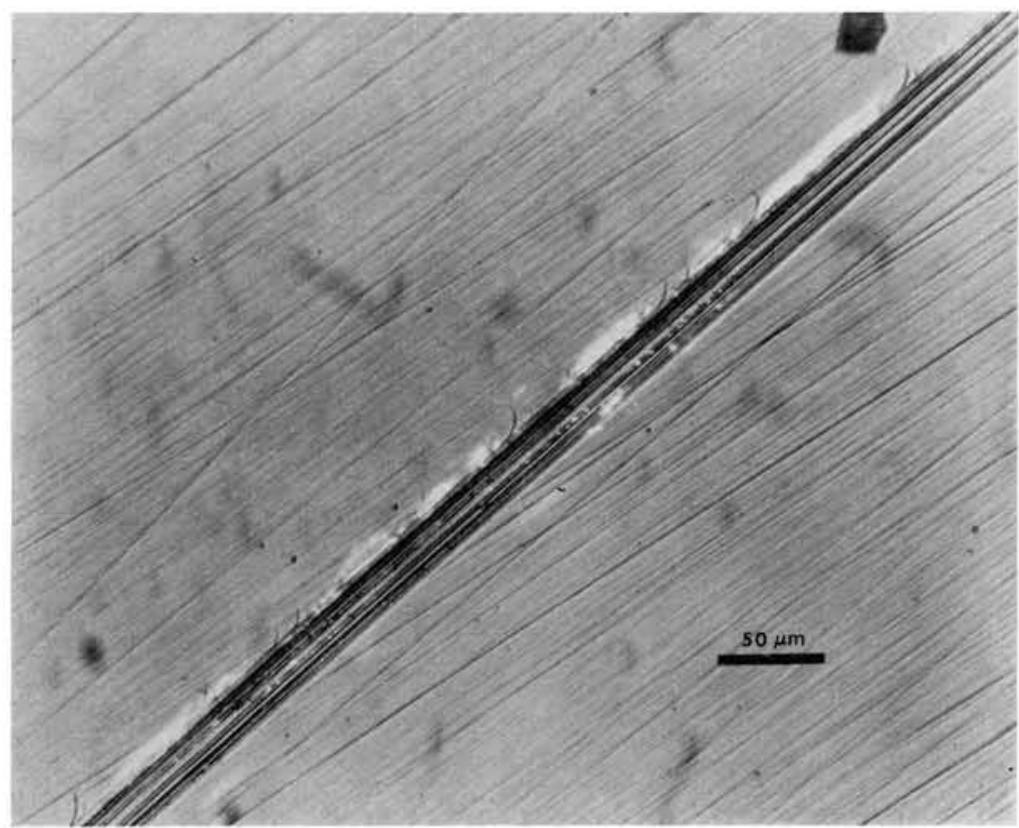

FIg 3.-Class 2 failure. 


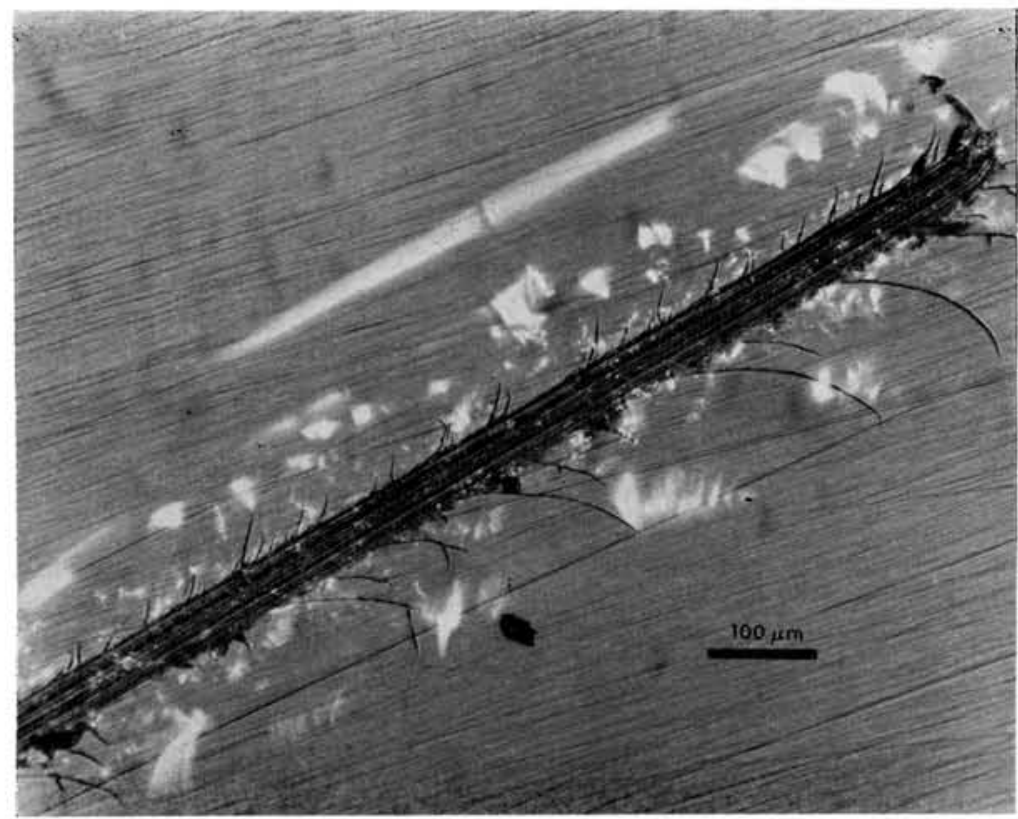

FIG 4.-Class 3 failure (cleavage mode).

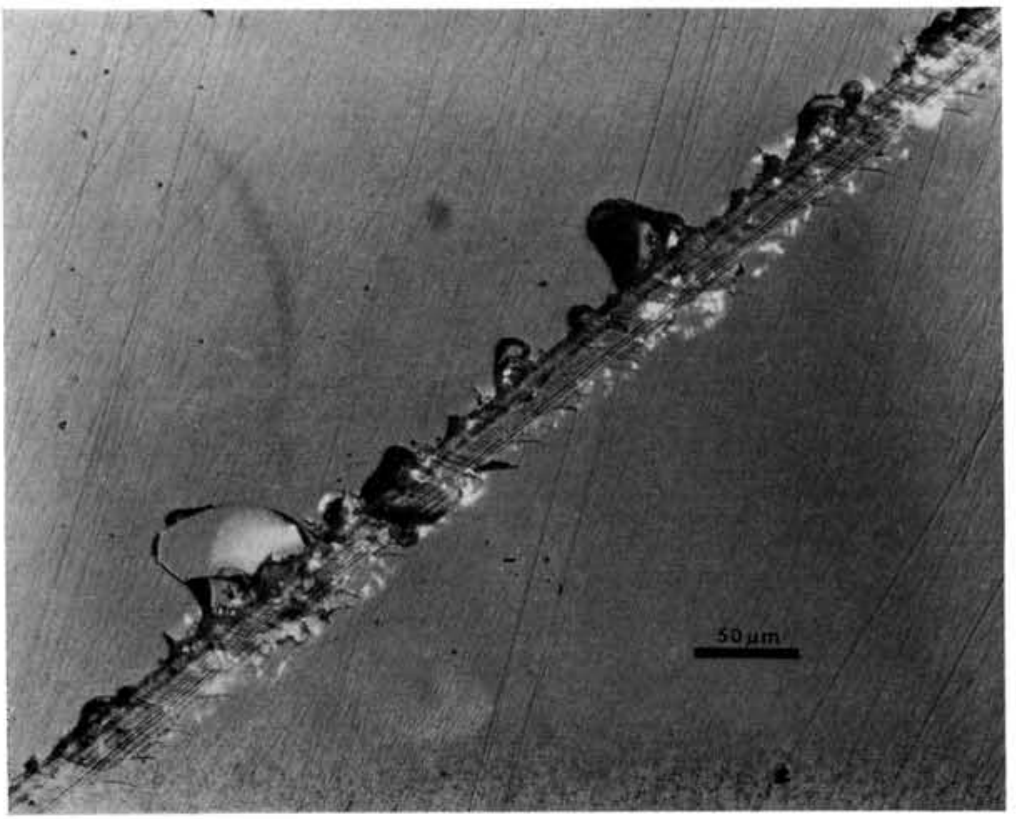

FIg 5.-Class 4 failure. 


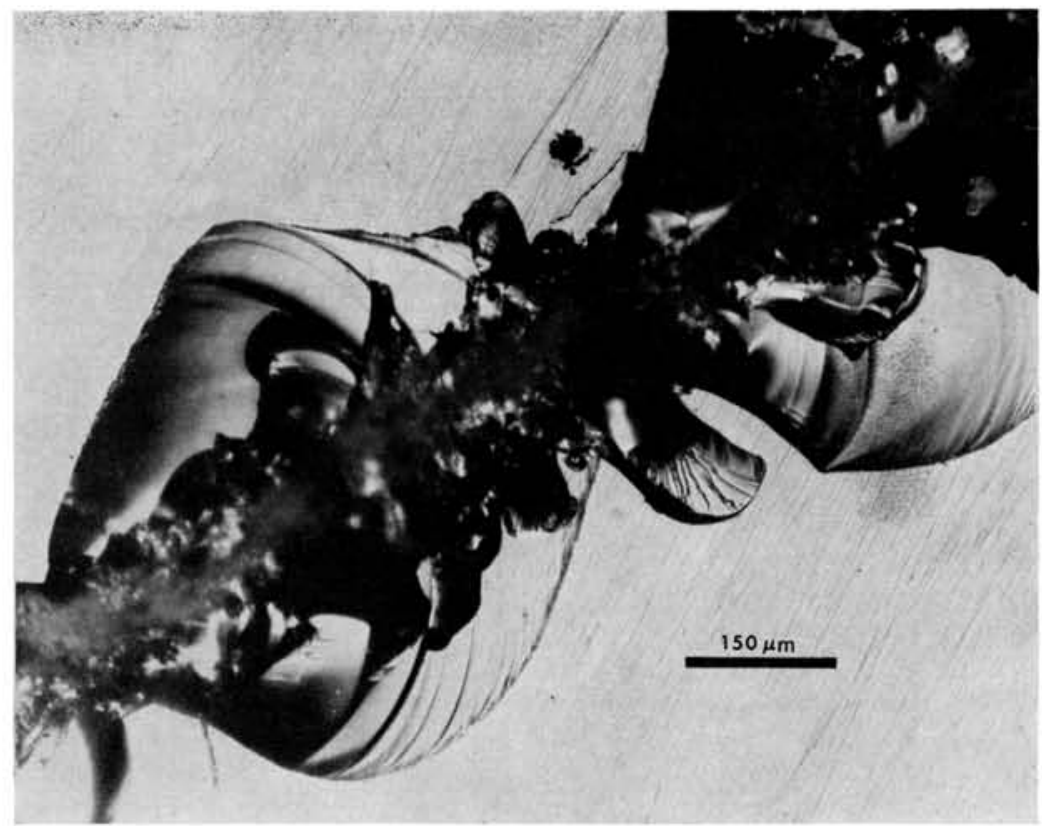

FIG 6.-Class 5 failure (chipping mode).

classification was examined at two levels with five loads and five slider designs with three replications per cell. It was deduced that there was probably no significant difference between the effects at two levels of specimen. Thus, the data for each level of specimen were combined to yield six replications per cell for subsequent analysis of the other factors.

The effect of speed on failure classification was examined at two levels $(0.025$ and $0.076 \mathrm{~cm} / \mathrm{second}$ ) for five slider designs at a load of $500 \mathrm{gm}$. Table 2 indicated that there were probably no significant differences between the effects at two levels of speed for slider designs $B_{3}$ through $B_{5}$. It appeared, however, for slider designs $B_{1}$ and $B_{2}$ that the lower speed resulted in a higher failure classification (ie, more cracking).

The effect of load on failure classification was examined at five levels $\left(A_{1}\right.$ through $A_{5}$ ) for five slider designs. It was deduced that there probably were significant differences among the effects at five levels of load. Load had little effect on failure classification for slider design $B_{2}$; its behavior was essentially ductile over the load range studied. Similar behavior was found for design $B_{1}$, except at the $500 \mathrm{gm}$ load where the mode of failure became cleavage with some chevron formation. Of the slider designs with small radii $\left(B_{3}\right.$ through $\left.B_{5}\right)$, only design $B_{3}$ exhibited ductile behavior at $10 \mathrm{gm}$. Above this load, these designs were characterized by class 4 or class 5 failure.

The effect of slider design on failure classification was examined at five levels $\left(B_{1}\right.$ through $\left.B_{5}\right)$ for five loads. Based on the data presented in Table 2 , it was deduced that there were probably significant differences among the effects at the five levels of design. At the lower loads $\left(A_{1}\right.$ through $A_{4}$ ), the designs could be pseudoranked in terms of increasing classification as follows: $B_{2}, B_{1}, B_{5}, B_{4}, B_{3}$. There probably was little difference between designs $B_{1}$ and $B_{2}$ or $B_{4}$ and $B_{5}$ at these loads. At the $500 \mathrm{gm}$ load, the behavior of designs $B_{3}$ through $B_{5}$ was similar (class 5). Designs $B_{1}$ and $B_{2}$ were ranked lower (class 4 and class 2 , respectively) than designs $B_{3}$ through $B_{5}$.

\section{Discussion}

The discrepancies in classification noted on examination of the raw data presented in Table 2 may be the result of three effects: anisotropy with respect to sliding direction, natural defects, defects introduced 
as the result of polishing, or all three. Possible anisotropic effects have been discussed previously. ${ }^{7,8}$ Even though in selecting and preparing the crystals an attempt was made to avoid obvious internal flaws such as inclusions, veils, and cleavages, flaws were present within $2 \mathrm{~mm}$ of the surface in most instances. Defects introduced as the result of polishing probably are most influential in determining the wear behavior of a particular crystal. In the extreme situation these defects would be manifested as subsurface cracks. More likely, however, polishing produces a substantial increase in surface and subsurface dislocation density (ie, prior strain). The extent of this prior strain would, of course, influence the failure mode of a crystal. It was assumed in this study that the polishing procedure introduced a similar amount of strain in all crystals.

This ordinal system of failure classification has the peculiarity of not being able to rank within a given class. Thus, the effect of slider speed on the failure classifications of slider designs $B_{3}$ through $B_{5}$ at a $500 \mathrm{gm}$ load could not be evaluated because the failure modes at both speeds were class 5 in appearance. Yet, a strain rate effect was observed for designs $B_{3}$ and $B_{4}$ with the wear data (such as track width) reported previously. ${ }^{7}$ On the other hand, a slight difference in failure mode was detected for designs $B_{1}$ and $B_{2}$, with more damage resulting at the lower speed. In this instance the differences could not be detected in the wear data. ${ }^{7}$ These seemingly ambiguous results probably are a result of the different levels of sensitivity inherent in the measurement and analysis of the two types of wear data. In spite of this, the trends observed in both instances were consistent, in that higher values of surface damage were observed at the lower strain rate. The influence of strain rate on crack propagation 7,8 is substantiated further.

The effects of load and slider design on failure classification were consistent with observations reported by Bowden and Brookes for MgO. ${ }^{4}$ They reported little surface damage over a range of loads between 10 and $350 \mathrm{gm}$ with the apical angle of the cone larger than $120^{\circ}$. Below a critical load, the surface damage with sharper angles was light; however, above the critical load the surface damage increased. In the present study, the surface behavior with large radii sliders $\left(B_{1}\right.$ and $\left.B_{2}\right)$ and with small radii sliders $\left(B_{3}\right.$ through $B_{5}$ ) at lower loads was essentially ductile with some evidence of tensile cracking at higher loads for designs $B_{1}$ and $B_{2}$. At the higher loads for designs $B_{3}$ through $B_{5}$, surface behavior exhibited predominantly tensile cracking and chevron formation. Above the critical load (or track width), the slider designs with sharper apical angles caused considerably more damage than did those designs with larger angles. These observations suggest that it is the interrelationship between load and slider design that influences the mode of surface failure.

Failure classification as a function of track depth ${ }^{7}$ was evaluated from data as represented in Figure 7 for slider design $B_{1}$. A ductile to brittle transition occurred for this design and other slider designs at penetrations of the order of $0.3 \mu \mathrm{m}$; ie, below penetrations of $0.3 \mu \mathrm{m}$, the failure mode of fuorapatite was essentially plastic in nature and above this value, tensile cracks of varying magnitude, depending on the particular slider design and load, were observed. In general, surface damage was low for penetrations ranging from 0.04 to 0.64 $\mu \mathrm{m}$. For penetrations of 1.0 to $25 \mu \mathrm{m}$, however, extensive tensile cracking and chevron formation were evident. These observations are similar to those made by Dobson and Wilman $^{5}$ for $\mathrm{NaCl}$ and Wright ${ }^{6}$ for human dental tissues under conditions of abrasion. These observations suggest that the basal plane of fluorapatite as prepared ${ }^{7}$ can accommodate plastic deformation corresponding to a hydrostatic compressive strain associated with penetration in the order of 0.3 to $0.5 \mu \mathrm{m}$. Additional compressive strain is relieved by tensile cracking (cleavage) immediately after the slider has passed. Deeper penetration results in plastic deformation with immediate initiation of chevrons.

It will be recalled that low values of friction $\overline{(f}=0.20)$ were found for penetrations ranging between 0.04 and $0.64 \mu \mathrm{m}$, whereas high values $\overline{(f}=0.45)$ were found for penetrations above $1.0 \mu \mathrm{m} .{ }^{8}$ The low and high friction regimes are seen to correspond to ductile and brittle surface be- 


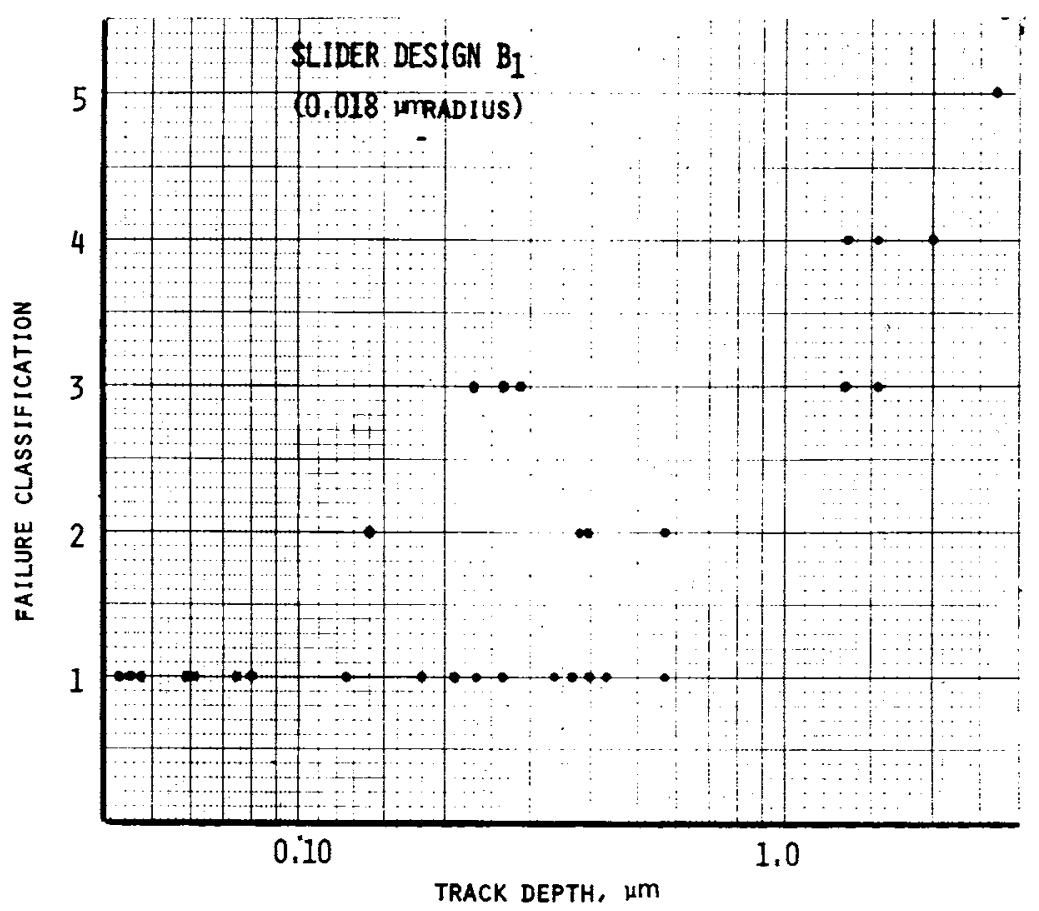

FIG 7.-Relationship between failure classification and track depth.

havior. In their study of $\mathrm{NaCl}$, Dobson and Wilman ${ }^{5}$ observed three types of friction and wear relationships in different ranges of penetration. For less than $0.5 \mu \mathrm{m}$ depth, fracture appeared to be absent and plastic flow predominated. For deeper penetration, friction increased linearly with wear rate, ie, with greatly increased wear. At indentations greater than $5 \mu \mathrm{m}$, the wear rate increased strongly without much further increase in friction. These observations suggest that friction on the basal plane of fluorapatite more than necessary to overcome adhesion is a function of the amount of energy necessary to deform the crystal plastically in compression. At a maximum strain, the high friction regime corresponds to the energy necessary to initiate chevron formation.

\section{Conclusions}

The modes of surface failure observed for natural fluorapatite single crystals under sliding were classified and related to wear and frictional behavior.

The data further supported the argument that the basal plane of fluorapatite is sen- sitive to strain rate, with lower strain rates causing greater surface damage.

The basal plane of fluorapatite behaved in a ductile manner for large diameter sliders over the range of loads studied and for small diameter sliders at the lower loads. At higher loads this behavior was transformed to a brittle mode of failure with tensile cracking followed by chevron formation. Small angle sliders caused more relative damage than did the larger angle sliders above a critical load. This suggested that it was the interrelationship between load and slider design that influenced the mode of surface failure.

A ductile to brittle transition occurred between penetrations of 0.3 and $0.5 \mu \mathrm{m}$ in the basal plane of fluorapatite. At penetrations greater than $1.0 \mu \mathrm{m}$, chevron formation and high friction were observed. This suggested that a compressive strain corresponding to a penetration of 0.3 to $0.5 \mu \mathrm{m}$ could be accommodated by plastic deformation. Above this strain tensile cracks would occur immediately on passing of the slider. At much greater penetrations, 
chevron formation would be initiated immediately.

\section{References}

1. KING, R.F., and TABOR, D.: The Strength Properties and Frictional Behavior of Brittle Solids, Proc Roy Soc (London) A 223: 225-238, 1954.

2. STEIJN, R.P.: Sliding and Wear in Ionic Crystals, J Appl Phys 34:419-428, 1963.

3. StEIJN, R.P.: Friction and Wear of Single Crystals, Wear 7:48-66, 1964.

4. Bowden, F.P., and Brookes, C.A.: Frictional Anistropy in Nonmetallic Crystals, Proc Roy Soc (London) A 295:244-258, 1966.
5. Dobson, P.S., and Wilman, H.: The Friction and Wear, and Their Interrelationship, in Abrasion of a Single Crystal of Brittle Nature, Brit J Appl Phys 14:132-136, 1963.

6. WRIGHT, K.H.R.: The Abrasive Wear Resistance of Human Dental Tissues, Wear 14:263-284, 1969.

7. Powers, J.M., and Craig, R.G.: Wear of Fluorapatite Single Crystals: I. A Method for Quantitative Evaluation of Wear, $J$ Dent Res 51:168-176, 1972.

8. Powers, J.M., and Craig, R.G.: Wear of Fluorapatite Single Crystals: II. Frictional Behavior, J Dent Res 51:605-610, 1972.

9. SIEGEL, S.: Nonparametric Statistics for the Behavioral Sciences, New York: McGrawHill, 1956. 